\title{
O GENOMA JURÍDICO-POLÍTICO DOS NOVOS DIREITOS
}

Cesar Luiz Pasold *

\section{RESUMO}

A partir de uma opção conceitual para a categoria Novos Direitos, busca-se a sua caracterização genético-jurídico-política e, em especial, o seu genoma, este identificado no Estado Contemporâneo que tenha compromisso com a Função Social. Nesta perspectiva são considerados, de forma indispensável e em interação, a legitimidade das ações de Estado e de Governo e o Pacto Ético entre Estado e Sociedade.

Palavras-chave: Estado Contemporâneo. Genoma jurídico-político. Legitimidade. Novos Direitos. Pacto Ético.

\section{O CONCEITO OPERACIONAL DA CATEGORIA "NOVOS DIREITOS” E O ESPECTRO BÁSICO DE SUA GENÉTICA JURÍDICA}

Para os efeitos do presente Ensaio, estou compreendendo a categoria "NOVOS DIREITOS" no sentido que, a partir das propostas originais de Norberto BOBBIO' e em Trabalho anterior, propus nos seguintes termos:

\begin{abstract}
Novos Direitos são o "resultado de uma multiplicação de Direitos em conseqüência de três fatores de propulsão: o aumento da quantidade de Bens considerados merecedores de Tutela; a extensão da titularidade de certos Direitos típicos a outros sujeitos que não o Homem; e, a consideração do Homem não mais como ente genérico ou "em abstrato", mas sim na concretude das maneiras dele ser em Sociedade. ${ }^{2}$
\end{abstract}

Do ponto do delineamento "molecular" dos Novos Direitos este conceito se apresenta como bastante adequado, a meu juízo e salvo melhor, porque ele exibe uma proposta de percepção do espectro básico de sua genética jurídica, o que significa um bom início de compreensão da totalidade desta genética.

Através dele se propõe que os Novos Direitos são produto de um movimento propulsor de partículas jurídicas de tríplice natureza, a saber :

1a - expansão quantitativa de bens para merecimento de tutela jurídica;

2 a $^{-}$extrapolação da titularidade de determinados Direitos além do Homem;

3-. ponderação forte para as maneiras de o Homem ser em Sociedade.

Ademais, a este importante retrato primitivo se acrescenta um fato real para o qual também Norberto BOBBIO nos despertou, com contundência, que 
é a ameaça de degenerescência jurídica destes avanços pela falta de sua concretização.

E BOBBIO verbalizou esta inquietação e não apenas com relação aos Novos Direitos, mas também no que concerne a todos os Direitos do Homem, de maneira contundente frisando que problema atual "não é filosófico, mas jurídico e, num sentido mais amplo, político"3.

\section{O GENOMA JURÍDICO-POLÍTICO DOS NOVOS DIREITOS: PRELIMINARES ESTRATÉGICAS}

Estou utilizando, no presente ensaio, a expressão "GENOMA JURÍDICO-POLÍTICO" para designar a constituição genético-jurídica total de um determinado elemento, no caso ora em estudo, a dos NOVOS DIREITOS.

Como propus no item anterior, compreendendo-se os Novos Direitos de uma determinada maneira, têm-se exibidos as primeiras moléculas de sua genética jurídica, a partir das quais será necessário agregar novas perspectivas, conhecimentos e reflexões para se alcançar uma possibilidade efetiva de radiografia confiável dela e que permita percebe-la na sua constituição genética, do ponto de vista jurídico e mesmo político, em seu todo.

Para alimentar solidamente tal pretensão é preciso preliminarmente enfrentar de modo objetivo dois temas fundamentais :

$1^{\circ}$ - a estratégica inserção dos Novos Direitos na categoria dos Direitos do Homem;

$2^{0}$ - o enfraquecimento - evitando-se a todo custo o desrespeito ou 0 menosprezo- da taxionomia que pode acabar por confinar os Novos Direitos em "gerações".

\subsection{Primeira preliminar}

No concernente a primeira preliminar,qual seja, a indiscutível inserção dos Novos Direitos na categoria Direitos do Homem, mantenho aqui a minha reiterada postulação no sentido de que a questão dos Novos Direitos não pode ser trabalhada de maneira integral se não for resgatada toda a "afirmação histórica dos Direitos Humanos", expressão feliz de Fábio Konder COMPARATO4. Aliás, da leitura do seu belíssimo ensaio intitulado "Sentido e Evolução dos Direitos Humanos" reafirmo e consolido aqui o meu aprendizado especial quanto a sete lições, que assim resumo:

1a - o núcleo dos Direitos Humanos é a Dignidade Humana;

2ª-há uma igualdade essencial entre os seres humanos que dá sustentação à liberdade e razão, independentemente de eventuais diferenças de sexo, raça, religião ou costumes sociais; 
$3^{\text {a }}$ - todos os seres humanos têm direito de ser igualmente respeitados por causa da sua humanidade;

$4^{\text {a }}$ - é fundamental a seguinte preleção kantiana:

a dignidade da pessoa não consiste apenas no fato de ser ela, diferentemente das coisas, um ser considerado e tratado como um fim em si e nunca como um meio para a consecução de determinado resultado. Ela resulta também do fato de que, pela sua vontade racional, só a pessoa vive em condições de autonomia, isto é, como ser capaz de guiar-se pelas leis que ele próprio edita;

$5^{\mathrm{a}}$ - por isto,

todo homem tem dignidade e não um preço como as coisas. A humanidade como espécie e cada ser humano em sua individualidade, é propriamente insubstituível: não tem equivalente, não pode ser trocado por coisa alguma;

6ㅁ- e ainda:

o conjunto dos direitos humanos forma um sistema correspondente à hierarquia de valores prevalecente no meio social; mas essa hierarquia axiológica pode não coincidir com a consagrada no ordenamento positivo. Há sempre uma tensão dialética entre a consciência jurídica da coletividade e as normas editadas pelo Estado;

$7^{\text {a }}$ - e, por fim, a conveniência de se manter a visão de HEIDEGGER conforme a qual o homem é dotado da característica singular de um "permanente inacabamento".

\title{
2.2 Segunda preliminar
}

No que concerne à segunda preliminar, vale dizer, àquela que enfatiza a questão da exigibilidade de uma taxionomia dos Novos Direitos "engessandoos" em "gerações", desde logo manifesto-me quanto a sua não obrigatoriedade, ainda que a reconheça como instrumento eficaz para verificação de sua gênese e processo evolutivo.

E assim me posiciono ex vi de minha repetida concordância com BRANDÃO, quando demonstra que, inclusive nos direitos tradicionais enquadrados como de Primeira Geração, há uma evolução/ampliação de concepção e enquadramento, respeitados os respectivos contextos históricos, que os inclui, sem dúvida, nos Novos Direitos ${ }^{5}$. Aliás, é significativo este trecho:

\begin{abstract}
Assim, é preciso ter claro que, quando de trata de "Novos" Direitos, deve-se atentar para o fato de que direitos de gênese individual que foram reconhecidos inicialmente em outro momento, podem estar inseridos no contexto desses novos direitos, porque na atualidade, sua conformação e sua forma de defesa - [...] - são de tal forma diversas que já não se pode mais enuncia-las como integrantes da Primeira ou da Segunda geração de direitos.
\end{abstract}

Feita esta colocação, e sem contraditar-me, recomendo que se leve em consideração este tipo de classificação porque, vênia pela repetição, a 
taxionomia tem o mérito de, didaticamente, evidenciar como se expressou concretamente aquele direito no contexto de um processo genético evolutivo que é oriundo de três movimentos jurídico-moleculares originais, que constituem o seu boom inicial, e que - permito-me repetir- são:

1 a - a expansão quantitativa de bens para merecimento de tutela jurídica;

$2^{\mathrm{a}}$ - a extrapolação da titularidade de determinados Direitos além do Homem;

$3^{\text {a }}$ - a ponderação forte para as maneiras do Homem ser em Sociedade.

OLIVEIRA JÚNIOR ${ }^{6}$ sugeriu que a melhor compreensão da "condição de sujeito de direito e cidadão", pode acontecer caso se considere aquilo que " Bobbio denomina uma evolução histórica e sucessiva dos direitos" , ampliandose em fases, denominadas gerações, desde a primeira na qual encontramos "os direitos individuais, que pressupõem a igualdade formal perante a lei e consideram o sujeito abstratamente ".

Segue-se a segunda geração na qual nos deparamos com "os direitos sociais, nos quais o sujeito de direito é visto enquanto inserido no contexto social, ou seja, analisado em uma situação concreta".

$\mathrm{Na}$ terceira geração pontificam os denominados "direitos transindividuais, também chamados direitos coletivos e difusos, e que basicamente compreendem os direitos do consumidor $e$ os direitos relacionados à questão ecológica".

Como de quarta geração, e em permanente estado polemístico- mercê, digo eu, tanto da confusão entre Ética e Moral quanto da necessidade efetiva de um pré-questionamento Ético - estão enquadrados "os direitos de manipulação genética relacionados à biotecnologia e bioengenharia, que tratam de questões sobre a vida e a morte".

$\mathrm{Na}$ quinta geração, estão " os advindos com a chamada realidade virtual que compreendem o grande desenvolvimento da cibernética na atualidade, implicando o rompimento de fronteiras, estabelecendo conflitos entre países com realidades distintas, via Internet'.

E já adiante se vão classificações enumerando novas gerações...!

Para os meus propósitos no presente Ensaio, os exemplos que se exibem nesta taxionomia de cinco gerações são suficientes para configurar um processo de reconhecimento jurídico acumulativo que, em sua completude $a^{a b e r t a}{ }^{7}$, se faz precisamente num momento (ou tipo, se se desejar) da dinâmica do Estado.

Sob tal diapasão, propugno que, mais exatamente, esta constituição genética dos Novos Direitos, ou o seu GENOMA JURÍDICO-POLÍTICO é a Constituição Política do ESTADO do tipo CONTEMPORÂNEO, como passo a defender em seguida. 


\section{DINÂMICA ${ }^{8}$ \\ 3 O ESTADO COMO CATEGORIA POLISSÊMICA, POLÊMICA E}

DALLARI adverte, quando estuda a "Origem e Formação do Estado", para a importância de se atentar às diversas noções de Estado adotadas pelas diversas correntes que se ocupam com o seu estudo, porque delas advém conclusões muito diferentes seja quanto à época seja quanto aos motivos determinantes para o nascimento dos Estados. três:

No que concerne à época de surgimento do Estado, DALLARI reduz a

$1^{0}$ - o Estado e a própria Sociedade ${ }^{10}$ teriam existido sempre;

$2^{\circ}$ - a Sociedade existiu sem o Estado durante um certo período, após o qual o Estado teria sido constituído buscando satisfazer as necessidade ou conveniências dos grupos sociais;

$3^{0}$ - o conceito de Estado não pode ser entendido como geral e válido para todos os tempos; é um conceito histórico concreto, tendo surgido quando nasceram a idéia e a prática da Soberania.

No que concerne aos motivos determinantes, CALMON ${ }^{11}$, levanta três possibilidades, a partir das manifestações doutrinárias historicamente postas:

$1^{\text {a }}$ - o Estado é divino, porque tem sua origem no sobrenatural;

$2^{a}$ - o Estado é humano, porque advém da Lei e, portanto, da "razão";

$3^{a}$-o Estado é social, porque resulta de uma evolução histórica.

Neste mesmo aspecto, JELLINEK ${ }^{12}$ apresenta cinco espécies de teorias: justificação teológica - religiosa; teoria da força; teorias jurídicas; teorias éticas e teoria psicológica. Critica-as por serem limitadas, na medida em que não procuram justificar a comunidade do Estado em sua totalidade, fixando-se num de seus elementos, em especial, no Poder de mando ou Poder coativo ("imperium").

Para DALLARI, a verificação da evolução histórica do Estado "significa a fixação das formas fundamentais que o Estado tem adotado através dos séculos", ressalvando a impossibilidade de se "dispor cronologicamente, em ordem sucessiva apoiada na história, os exemplos de Estado que tenham realmente existido uns após os outros"13. Portanto, qualquer retrospectiva sempre é, de certa forma, especulativa. Além disto, é pertinente a advertência de HELLER ${ }^{14}$.

Para compreender melhor as relações políticas do passado, não há, em última análise, outro recurso senão medi-los com os conceitos do pensar atual.

[...] Por este meio, se se quiser evitar ter imagens totalmente falsas do passado, deve usar-se o mesmo com a máxima cautela e na 
compreensão de que os nossos conceitos políticos são inadequados, em princípio, para um passado bastante remoto.

\section{NOTÍCIA SOBRE A PROPOSTA DE JELLINEK DE CINCO TIPOS HISTÓRICOS FUNDAMENTAIS DE ESTADO APROPRIADOS COMO ESTÁGIOS DO PROCESSO EVOLUTIVO ESTATAL}

Sem descuidar das restrições até aqui apontadas, resumo a proposta de JELLINEK de cinco tipos históricos fundamentais de Estado ${ }^{15}$, entendendo, sobretudo, que eles podem, com cautela, ser apropriados como estágios do processo genético-jurídico evolutivo estatal, conforme o seguinte:

10 - Antigos Estados Orientais: dentre os quais o Estado mais importante, segundo o Autor citado, é o Israelita, pela influência que exerceu quer na constituição da Igreja primitiva, quanto na ideologia política da Idade Média e da Época Moderna. Ainda que não possa referir a uma participação regulamentada do povo no governo do Estado Israelita, "muitas vezes: rei e povo contraem obrigações mútuas na forma de um pacto diante de Jeová";

20 - Estado Helênico: desvalorizando completamente o indivíduo perante o Estado, o seu ponto fundamental reside na sua "onipotência". A propósito, DALLARI ${ }^{16}$ enfatiza o quanto foi limitativa a democracia helênica, na qual apenas os "cidadãos" eram partícipes das decisões políticas, sendo que o conceito de cidadão era, então, muito restritivo;

3ำ - Estado Romano: apresenta diversas semelhanças com o Estado Helênico, mas "o sagaz espírito jurídico dos romanos", para JELLINEK, reconheceu a dualidade da qualidade de cidadão: titular de exigências a prestações do Estado e de direitos de participação na vida do mesmo. CALMON, de sua parte, registra a posição do Estado (isto é, a Cidade) como uma super-ordem, na qual família e propriedade são elementos principais e sagrados, e a noção de que "o individuo é ser sujeito de direito, membro da corporação política, cidadão"17. ENGELS, por sua vez, descreve em que ponto se encontrava este Estado "nos fins do século $V$ " quando era "débil, exangue e impotente..." Prossegue, crítico: "O Estado romano se tinha tornado uma máquina imensa e complicada, destinada exclusivamente à exploração dos súditos; impostos, prestações pessoais ao Estado e gravames de todas as espécies mergulhavam a massa do povo numa pobreza cada vez mais aguda. As extorsões dos governadores, dos fiscais e dos soldados reforçavam a opressão, tornando-a insuportável." 18

4ํ - Estado da Idade Média: JELLINEK alerta para o fato de que a característica do Estado Antigo de ser uma unidade geral que não admitia divisão interior, sofreu, na evolução do Estado da Idade Média, uma reversão de expectativa.

O exemplo que JELLINEK destaca é o Estado Germânico que, ao início, foi uma "associação de povos", na qual estava ausente a constante relação com um território fixo e, tal vínculo permanente do povo com um território foi construído lentamente em sua história. ${ }^{19}$ 
Neste tipo de Estado encontra-se uma relação especial com a Igreja. HELLER descreve, historicamente, tal fenômeno assim: "Na Antiguidade, Estado e Igreja, grupo político e grupo cultural, haviam constituído uma unidade inseparável; cada "polis" tinha os seus próprios deuses". A situação se altera, para o referido Autor, com o monoteísmo judeu-cristão: "formou-se uma Igreja universal, independente das fronteiras políticas, que tirou boa parte da vida pessoal e pública da dominação do grupo político.". No entanto, na Idade Média, configura-se um panorama específico: a Igreja reclamou uma obediência, embora extra-estatal, política, de todos os homens, inclusive dos que exerciam o Poder político, a ela obrigando, em muitos casos, por eficazes meios coativos espirituais e mesmo físicos. Desta maneira, a lgreja limitava o Poder político medieval não só exteriormente mas, de modo mais intenso, no interior, indiretamente, valendo-se do clero". O final deste quadro se fez com a reforma protestante que "trouxe como conseqüência a emancipação definitiva e total do Poder do Estado a respeito da Igreja, inclusive nos Estados católicos" 20 Ainda assim, JELLINEK pondera que a Igreja ofereceu aos Estados da Idade Média um exemplo vivo e permanente de uma associação unitária.

Já DALLARI observa que não é tarefa fácil a busca de características de um Estado Medieval porque a Idade Média, no plano do Estado, desenha-se como um dos períodos mais difíceis da história política, caracterizado por dois fatores de alta significância : (1) a instabilidade, e (2) a heterogeneidade.

Apesar disto, o mesmo DALLARI propõe que três fatores conjugados (o cristianismo, a invasão dos bárbaros e o feudalismo) caracterizariam mais "como aspiração do que como realidade" o Estado na Idade Média, com a presença de alguns elementos - tais como o Poder superior, o Imperador, a pluralidade sem definição hierárquica de Poderes menores e a variedade imensa de ordens jurídicas - que levavam a um quadro de instabilidade, provocando o "germe da criação do Estado Moderno", qual seja, a necessidade de ordem e de Autoridade ${ }^{21}$.

SOUZA $^{22}$, entretanto, esboça tal tipo de Estado, assim:

$\mathrm{Na}$ Sociedade medieval, o Estado - se é que se pode empregar esta expressão para as realidades políticas daquela época - se reduzia à pessoa do Soberano e às dos poucos homens de projeção que a assessoravam ou formavam seus Conselhos. ${ }^{23}$

HELLER $^{24}$ chega ao ponto de considerar duvidosa a denominação Estado Medieval2 ${ }^{25}$, argumentando:

É patente o fato de que durante meio milênio, na Idade Média, não existiu o Estado no sentido de uma unidade de dominação, independentemente no exterior e interior que atuava de modo contínuo com meios de Poder próprio, e claramente delimitada pessoal e territorialmente;

5ำ - Estado Moderno: seu núcleo genético está na sua condição de macro unidade de associação. Sua organização sustenta-se numa Constituição, porque nele se exibe uma dupla dicotomia expressa em rei e povo, e em poder espiritual e temporal. ${ }^{26}$.Tal fenômeno apresentou componentes peculiares em cada Estado em particular. Quanto à polêmica 
entre o Estado e a Igreja, ela teria sido decidida em beneficio do Estado, por força da denominada Reforma Protestante, e isto ocorreu não apenas nos Países nos quais os protestantes eram maioria.

O aspecto da unidade merece referências especiais e, para JELLINEK, a idéia da unidade resulta de uma grande evolução histórica, propondo que o Estado Moderno tenha como ponto final o que para o Antigo era o ponto de partida.

Quanto ao aspecto "relação indivíduo e Estado" o mesmo JELLINEK adverte que, na Antigüidade fez-se ausente a consciência do direito do indivíduo de possuir uma esfera de Liberdade frente ao Estado. Na época moderna, de forma diferente, mesmo sob a adversidade do absolutismo sem limites, fazia-se presente a convicção de que o indivíduo era um ser de direitos frente ao Estado e de que, tanto no plano moral quanto no âmbito jurídico, esse mesmo indivíduo deveria ser reconhecido pelo Estado. ${ }^{27}$

\section{PROPOSTA DE COMPREENSÃO DE SEXTO TIPO DE ESTADO OU SEXTO MOMENTO DO PROCESSO EVOLUTIVO ESTATAL}

Para completar a tipologia até aqui sucintamente apresentada, reafirmo minha proposta de um sexto tipo de Estado ou sexto momento do processo evolutivo estatal ${ }^{28}$.

Tenho defendido reiteradamente a tese de que em 1916 encerrou-se, do ponto de vista do Discurso Constitucional, o período do tipo Estado Moderno.

Com a Constituição Mexicana de $1917^{29}$ inicia-se o desenho de um Estado que, pelas suas condições muito peculiares proponho seja denominado Estado Contemporâneo. ${ }^{30}$

$\mathrm{Na}$ verdade, pleiteio que se aplique tal denominação ao espectro de variações dos diversos Estados que se apresentam na contemporaneidade - ou seja, de 1917 até o presente, 2008 - os quais, independentemente da motivação ideológica de suas Constituições, têm alguns denotativos essenciais que lhe são comuns e, principalmente, possuem uma função que lhes é, a todos, essencial.

O Estado é, nesta perspectiva, uma das instituições criadas pela Sociedade. Tal instituição se faz diferenciada de outras porque, além de deter o poder da coação oficial, tem como papel especializar-se e dedicar-se aos assuntos pertinentes ao Bem Comum ou Interesse Coletivo do Todo Social.

Parenteticamente é preciso registrar que nas pesquisas que realizei procurando uma retrospectiva quanto ao Estado e às doutrinas a ele relativas, percebi, muitas vezes, a utilização meramente retórica da categoria Bem Comum ou Interesse Coletivo sem conseqüências práticas significativas em benefício das Sociedades. Pondero, portanto, que a questão do Bem Comum ${ }^{31}$ ou Interesse Coletivo só poderá ser convenientemente equacionada caso o 
Estado seja realmente encarado e atue sempre como um instrumento de toda a Sociedade, e não apenas como agente de segmentos privilegiados por motivos de ordem econômica, racial, social, cultural, religiosa ou ideológica.

Neste momento, considero necessário alertar quanto ao fato de que não estou, aqui, vinculando a noção de Bem Comum exclusivamente com a idéia de Estado de Bem Estar, porque esta espécie de Estado possui vínculos com uma concepção neo-liberal, com o que, a meu juízo e salvo melhor, a sua dinâmica acaba por ser não suficiente para o atendimento das legítimas aspirações da Sociedade Contemporânea. ${ }^{32}$

Também não considero o denominado Estado Providência como o adequado para atender efetivamente a Função Social do Estado Contemporâneo, sobretudo porque concordo com POULANTZAS ${ }^{33}$ em sua crítica dinâmica reativa na qual destaca a timidez da mobilização popular nesta espécie de Estado, o que, em minha opinião, o desqualifica como o Estado adequado para a contemporaneidade, eis que não é legitimamente pró-ativo ${ }^{34}$.

Mantenho minha postura anterior, fruto de continuados estudos, prosseguindo no objetivo de consagrar uma concepção para o Estado Contemporâneo que não se sustente apenas na Doutrina Jurídica, indo além, especialmente alçando os campos da Teoria Política, da Filosofia Política e da Ética.

Quanto a esta última, é pertinente registrar o conceito operacional com o qual trabalho a categoria Ética e que tenho proposto nos seguintes termos:

ÉTICA é a atribuição de valor ou importância a pessoas, condições e
comportamentos e, sob tal dimensão, é estabelecida uma noção
específica de Bem a ser alcançada em determinadas realidades
concretas, sejam as institucionais ou sejam as históricas. ${ }^{35}$

Com ênfase, diferencio a Ética da Moral, e proponho para MORAL o conceito operacional que a compreende como uma "disposição subjetiva de determinação do que é correto e do que é incorreto, e, sob tal pressuposto, estabelecer-se uma noção própria do Bem e do Mal"36.

Portanto, adotados estes conceitos não há como confundir as duas categorias, podendo-se admitir, entretanto, uma conexão possível entre ambas em relação sinérgica ou de causação circular acumulativa.

Do ponto de vista da minha proposta de compreensão de Estado Contemporâneo há pois que pontuar destacadamente a Ética para retomar o tema do Bem Comum, agora desenhando a sua fundamentação.

Quando a Ética é ressaltada, surge conseqüentemente a expectativa de que haja uma profunda, contínua e sólida interação da Sociedade com o Estado no processo atributivo de importância ou valor para pessoas, condições, condutas, compondo-se e renovando-se continuamente uma noção de Bem Comum. Esta dinâmica quando efetivamente ocorre estabelece um padrão adequado e renovado para o exame da legitimidade dos atos de Governo e das ações de Estado. Neste diapasão, em nenhum momento, é 
permitido deixar de considerar as relevantes questões sociais que ocupam, de maneira contundente, o quadro da vida das Sociedades neste novo século/milênio.

Realizei, há cerca de cinco anos (em 2003) um re-exame dos Discursos Constitucionais de 58 (cinqüenta e oito) Estados contemporâneos que eu havia pesquisado cerca de 21 (vinte e um) anos antes (realizada, pois, em 1982), e confirmou-se minha constatação anterior: qualquer que seja a opção ideológica que os fundamente, eles mencionam compromissos formais do Poder Público com a Sociedade e com a realização dos anseios desta Sociedade.

Estas Constituições estabelecem portanto, as bases do que denomino processo atributivo de importância ou valor para pessoas, condições, condutas, possibilitando, portanto,fundamentalmente a composição e a renovação continuada da noção de Bem Comum para aquela vida política, ou seja, Sociedade e Estado se comprometem, entre si, de maneira ética, em termos de Interesse Coletivo, para uma dada circunscrição cronológica.

O mais importante é que há nestas Cartas Constitucionais, sem dúvida, uma atitude constitucional comum em direção à realização dos anseios sociais, com o que se coloca o traço fundamental de um desenho apropriado para a caracterização da FUNÇÃO SOCIAL do Estado Contemporâneo.

Infelizmente a observação da prática vivenciada em muitos destes Estados contemporâneos demonstra que a atitude constitucional de compromisso ético entre Sociedade e Estado, nem sempre se traduz em comportamentos coerentes, especialmente por parte do Estado, com 0 Discurso Constitucional.

Ademais, prossegue (e assim o vejo desde minhas observações iniciadas em 1981 - estas há 27 anos, pois) a ausência, a nível teórico, de uma caracterização a mais descritiva possível da FUNÇÃO SOCIAL - como categoria jurídica e política-habilitada para o seu ajuste instrumental ao fundamento ideológico da condução do Poder de cada Estado Contemporâneo. Nesta perspectiva tal caracterização pode ser efetuada numa perspectiva meta-ideológica ${ }^{37}$.

O princípio de $\mathrm{BOBBIO}^{38}$, de que "todas as teorias sobre as formas de governo apresentam dois aspectos: um descritivo e outro prescritivo", por conveniência ao raciocínio que estou expondo, pode ser adaptado e utilizado para minhas sucintas formulações quanto ao Estado Contemporâneo.

Para tanto, é necessário localizar cronologicamente o Estado Contemporâneo, o que fiz, de forma objetiva retro, quando sugeri o Sexto Tipo de Estado ou Sexto Momento Histórico de Estado.

Operando com o referente "Discurso Constitucional", reafirmo minha proposição no sentido de que, o surgimento do Estado Contemporâneo ocorreu na segunda década do Século XX, mais precisamente em 1917, com a Constituição Mexicana, confirmando-se, logo em seguida, em 1919, com a Constituição Alemã de Weimar, porque nestes dois Discursos Constitucionais 
se encontram regras que expressam características nodais que compõem este tipo de Estado.

Para melhor compreensão desta evolução, faz-se necessário pontuar, insistentemente aqui, que o aspecto destacado do Estado Moderno com relação aos momentos anteriores da etiologia estatal foi o de estabelecer um ordenamento constitucional. Nele, um elenco de Direitos Individuais estava devidamente especificado e consagrado como "anteparo" aos abusos do Estado anterior, no qual reinava o absolutismo e predominava a vontade e os apetites do Soberano, personificado no Rei ou no Imperador, em detrimento dos legítimos anseios e necessidades do Povo.

Ora, o Estado que denomino Contemporâneo avança significativamente com relação ao tipo ou momento histórico anterior e tal avanço torna indiscutível e definitiva a diferença entre o chamado Estado Moderno e o Estado Contemporâneo, porque este último:

1) mantém consagrados os Direitos Individuais;

2) insere como Direitos Fundamentais ${ }^{39}$ também os Direitos Sociais e/ou os Direitos Coletivos; e

3) para assegurar a efetiva realização desses Direitos estabelece a possibilidade e disciplina a intervenção do Estado nos domínios econômico e social.

Em minha opinião a primeira Constituição a expressar a tríade acima é a Constituição Política dos Estados Unidos Mexicanos, promulgada em 5 de fevereiro de $1917 .{ }^{40}$

Tem-me bastado para tal convencimento (e espero que seja também suficiente para o meu Leitor) o teor dos artigos 25 e 26 da referida Constituição ${ }^{41}$, assim versados:

Art. 25. - Corresponde ao Estado o compromisso com o desenvolvimento nacional para garantir que este seja integral, que fortaleça a soberania da Nação e seu regime democrático e que, mediante o fomento do crescimento econômico e o emprego de uma mais justa distribuição do ingresso e da riqueza, permita o pleno exercício da Liberdade e da dignidade dos indivíduos, grupos e classes sociais, cuja segurança protege esta Constituição.

O Estado planejará, conduzirá, coordenará e orientará a atividade econômica nacional, e levará a cabo a regulação e fomento das atividades que demandem o interesse geral no marco de Liberdades que outorga esta Constituição.

Ao desenvolvimento econômico nacional concorrerão, com responsabilidade social, o setor público e o setor privado, sem menosprezo de outras formas de atividade econômica que contribuam ao desenvolvimento da Nação.

ART. 26. - O Estado organizará um sistema de planejamento democrático do desenvolvimento nacional que imprima solidez, dinamismo, permanência e eqüidade ao crescimento da economia para a independência e a democratização política, social e cultural da Nação. ${ }^{42}$ 
Este texto que revela uma concepção jurídico-política avançada para a sua época é datado de 1917!

De forma pontual COMPARATO ${ }^{43}$ registra que

a Constituição Mexicana, em reação ao sistema capitalista, foi a primeira a estabelecer a desmercantilização do trabalho, ou seja, a proibição de equipará-lo a uma mercadoria qualquer, sujeita à lei da oferta e da procura no mercado. Ela firmou o princípio da igualdade substancial de posição jurídica entre trabalhadores e empresários na relação contratual de trabalho, criou a responsabilidade dos empregadores por acidentes do trabalho e lançou, de modo geral, as bases para a construção do Estado Social de Direito.

URBINA ${ }^{44}$, por sua vez, muito apropriadamente classifica a Constituição Mexicana de 1917 como "la primera DECLARACIÓN DE DERECHOS SOCIALES DEL MUNDO".

$\mathrm{E}$, a partir desse pioneirismo do Discurso Constitucional Mexicano, segue-se uma sucessão de Constituições com conteúdos na linha desse padrão, entre as quais destaco a já referida alemã de 1919 e a brasileira de $1934 .{ }^{45}$

\section{O ESTADO CONTEMPORÂNEO : SITUAÇÃO ATUAL}

A partir das três Constituições acima apontadas, e em seqüência, 0 Estado Contemporâneo foi se compondo em suas características fundamentais, as quais evoluem nos anos seguintes, de modo que atualmente os Discursos Constitucionais, numa perspectiva descritiva:

1-- conformam o Estado juridicamente, isto é, há consagrações formais dos conteúdos que o caracterizam em grande parte dos Países do Mundo, correspondendo em maior ou menor medida às realidades ali existentes, e sempre sob a égide das Ideologias que os fundamentam;

$2^{\circ}$ - com variações redacionais, estabelecem a submissão do Estado à Sociedade, com referências explícitas à origem do Poder estatal como sendo a Nação ou Povo ${ }^{46}$;

$3^{\text {- }}$ da mesma maneira formalizam constitucionalmente o compromisso dos Estados para com os anseios de suas Sociedades ${ }^{47}$;

4ํ - de modo geral, o Estado Contemporâneo tem assumido uma estrutura tentacular que é objeto de estudos, constatações e propostas de cientistas que têm a "burocracia como centro de atenção" $o^{\text {"18. }}$. As superestruturas são montadas para o exercício ampliado das funções estatais, ocorrendo hipertrofias em graduações variadas, na medida em que são examinados diversos Estados. Para POULANTZAS, por exemplo, "o estatismo autoritário caracteriza-se por uma dominação das cúpulas do executivo sobre a alta administração e pelo crescente controle político desta por aquela"49; 
$5^{\text {o }}$-em decorrência da internacionalização da economia (e da globalização ${ }^{50}$ ) sob o princípio (discutível) de que "as nações não podem viver isoladas mais eficientemente do que os indivíduos'51, e numa distorção progressiva dela através da desnacionalização do fluxo internacional de bens, crescentemente dirigido pelo que se convencionou denominar multinacionais, prospera em muitos Estados Contemporâneos, a mentalidade da primazia absoluta do econômico, em detrimento das contundentes questões sociais e ecológicas.

De outra parte, sob uma perspectiva prescritiva, proponho que tais características sejam compostas da seguinte maneira:

$1^{0}$ - as conformações jurídicas necessitam guardar relação fiel com a realidade que lhes cabe representar e regular;

$2^{0}$ - as colocações juridicamente estabelecidas quanto à submissão do Estado à Sociedade, pressupõem que sejam fixados e eficientemente operados os mecanismos políticos voltados para a realização dos princípios que as sustentam;

$3^{0}$ - o reconhecimento constitucional e infra-constitucional dos compromissos do Estado para com a Sociedade que o mantém, não é suficiente quando desacompanhado do aparelhamento institucional e administrativo, necessário à sua consagração prática;

$4^{0}$ - os fundamentos e as modernas técnicas para um desempenho administrativo eficaz somente se justificam se todo o conjunto tentacular estiver submisso às demandas que, em função da realidade, a Sociedade reclama que sejam atendidas com presteza pelo Estado Contemporâneo;

5ํ - o Estado Contemporâneo deve comportar-se sob a égide da primazia do humano, submetendo o econômico à força social.

O que proponho, com ênfase, é que o Estado seja um instrumento eficaz a serviço do Todo Social.

Nesta perspectiva, o Estado deve ser um conjunto de atividades legítimas e efetivamente comprometidas com uma Função Social, esta entendida como uma dinâmica de ações que - por dever para com a Sociedade - o Estado executa, respeitando, valorizando e envolvendo o seu Sujeito (que é o Homem individualmente considerado e inserido na Sociedade), em correspondência ao seu Objeto (conjunto de áreas de atuação que dão causa às ações estatais) e cumprindo o seu Objetivo (o Bem Comum ou Interesse Coletivo, fixado de forma ética e em dinâmica pelo Todo Social).

A Função Social que o Estado Contemporâneo deve ter e cumprir somente se viabilizará, em minha opinião, quando exista permanente legitimidade não apenas na consecução da vida política, mas também na vivência jurídica. 


\section{CONSIDERAÇÕES FINAIS}

Enfim, é possível admitir-se que o Estado Contemporâneo, nas diversas matizes em que se apresenta atualmente, seja o Genoma Jurídico-Político dos Novos Direitos especificamente quando dois fatores se completam em sólida interação, numa ou mais das diversas realidades nacionais:

10 - o ambiente jurídico-político é de constante Legitimidade, ou seja, ocorre a prática permanente das medidas clássicas de verificação da Legitimidade( eleições diretas, secretas, universais e periódicas, plebiscitos e referendos) dos detentores de Poder governamental e das Ações de Estado e de Governo, com o que se pode constatar a adequação dos ajustes éticos a efetuar. Por óbvio,há que se registrar aqui que, para conduzir tal processo, os Governantes do Estado Contemporâneo devem ser sempre detentores temporários do Poder Estatal e legitimados de forma constante;

2o - o Pacto Ético entre Sociedade e Estado se traduz em ações de Estado e em práticas de Governo que conferem efetiva prioridade para a realização de valores fundamentais do Homem (com a coerente atuação em favor do Meio Ambiente, Saúde, Educação, Trabalho, Liberdade, Igualdade) e, portanto, existe a primazia para os direitos individuais, trans-individuais, coletivos e sociais que integralizam a dignidade humana.

\section{THE LEGAL-POLITICAL GENOME OF THE NEW RIGHTS}

\section{ABSTRACT}

From a conceptual option for the category New Rights, is seeking its genetic characterization-legal-political and, particularly, its genome, identified in this state who has Contemporary commitment to Social Function. In this perspective are considered, so vital and interaction, the legitimacy of the actions of State and Government and Ethics Pact between State and Society.

Keywords: Ethics Pact. Genome legal-political. Legitimacy. New Rights. State Contemporary.

\section{NOTAS}

Doutor em Direito do Estado pela Faculdade de Direito do Largo São Francisco da Universidade de São Paulo-USP; Pós-Doutor em Direito das Relações Sociais pela Universidade Federal do Paraná-UFPR; Mestre em Saúde Pública pela Universidade de São Paulo-USP; Mestre em Direito pela Universidade Federal de Santa Catarina- UFSC. Advogado - OAB/SC 943 e Diretor Presidente do Advocacia Pasold e Associados OAB/SC-059/90. Professor do Curso de Pós Graduação Stricto Sensu em Ciência Jurídica da UNIVALI. Consultor Científico da UNOESC.Consultor ad hoc da Fundação Capes. Autor, entre outros, dos livros : Prática da Pesquisa Jurídica e Metodologia da Pesquisa Jurídica (10. ed. rev. amp. Florianópolis: OAB/SC Editora, 2007); Lições Preliminares de Direito Portuário. (São José/SC: Conceito Editorial, 2007); Técnicas de Comunicação para o Operador Jurídico (2. ed.rev.atual. Florianópolis: OAB/SC Editora,2006); Função Social do Estado Contemporâneo (3. ed.rev.atual.amp. Florianópolis: OAB/SC Editora co-edição 
Editora Diploma Legal, 2003); e, O Advogado e a Advocacia (3. ed. Florianópolis: OAB/SC Editora, 2001).

1 Conceito composto com base em BOBBIO, Norberto. A Era dos Direitos, Tradução de Carlos Nélson Coutinho. 5 reimp. Rio de Janeiro: Campus, 1992. p. 68.Título original: L' Etàt dei Diritti. p. 68.

2 Vide PASOLD, Cesar Luiz. Novos Direitos: Conceitos Operacionais de cinco Categorias que Ihe são conexas. In: Revista Seqüência, no 50, p. 225-236, jul. 2005.

3 BOBBIO, Norberto. A Era dos Direitos, cit. p. 25.

4 COMPARATO, Fábio Konder. A Afirmação Histórica dos Direitos Humanos. 2. ed. Ver. e ampl. São Paulo: Saraiva, 2001.

5 Vide BRANDÃO, Paulo de Tarso. Ações Constitucionais: novos direitos e acesso à justiça. 2. ed. rev. amp. Florianópolis: OAB/SC Editora, 2006, em especial, p. 149 a 162. O trecho acima transcrito encontra-se na p. 150.

6 Conforme OLIVEIRA JÚNIOR, José Alcebíades de. Teoria Jurídica e Novos Direitos. Rio de Janeiro: Lumen Juris, 2000 , p.85 e 86 . Procurei manter certos trechos em transcrição literal, em homenagem à fidelidade expositiva do texto original, de inegável valor teórico e histórico.

7 Sinto-me à vontade para empregar esta expressão aparentemente incoerente, porque penso que este reconhecimento jurídico acumulativo é completo até as respectivas formalizações, mas permanece aberto para novos reconhecimentos, por isto nele ocorre uma "completude aberta".

8 A partir daqui estou procurando sintetizar e em alguns momentos pontuais pretendo avançar, para os propósitos deste Ensaio, as idéias expostas em PASOLD, Cesar Luiz. Função Social do Estado Contemporâneo. 3. ed. rev. atual. amp. Florianópolis: OAB/SC Editora co-edição Editora Diploma Legal. 2003.

9 DALLARI, Dalmo de Abreu. Elementos de Teoria do Estado. São Paulo: Saraiva, 1987. p. 43-50.

10 Advirto ao Leitor que, no presente texto, a palavra Sociedade estará grafada com a letra inicial em maiúscula. E assim o é porque estou convencido da seguinte lógica: se a Categoria ESTADO merece ser grafada com a letra E em maiúscula, muito mais merece a Categoria SOCIEDADE ser grafada com a letra $\mathrm{S}$ em maiúscula, porque, afinal, a SOCIEDADE é a criadora e mantenedora do Estado! Por coerência, pois, se a criatura/mantida (Estado) vem grafada com $E$ em maiúscula, também e principalmente a criadora/mantenedora (Sociedade) deve ser grafada com o $\mathrm{S}$ em maiúscula! Assim já o fiz, entre outros momentos, no meu Livro PASOLD, Cesar Luiz. Prática da Pesquisa Jurídica e Metodologia da Pesquisa Jurídica. 10. ed. rev. amp. Florianópolis: OAB/SC Editora, 2007, p. 200-201, nota oㅜ 154.

11 CALMON, Pedro. Curso de Teoria Geral do Estado. Rio/São Paulo: Freitas Bastos, 1964. p. 34.

12 Sobre as teorias apresentadas vide: JELLINEK, Georg. Teoria General Del Estado. Tradução de Fernando de Los Rios Urruti. México, D. F: Compañia Editorial Continental, s.d. p. 496 e 497 (sem título original no exemplar utilizado). A respeito da proposta de JELLINEK, vide DALLARI, Dalmo de Abreu. Da Atualização do Estado. São Paulo: Edição do Autor, 1963. p. 125-130.

HELLER, Herman. Teoria do Estado. Tradução de Lycrugo Gomes da Motta. São Paulo: Mestre Jou, 1968. Título original: Staatslehre. Sobre os pontos básicos da teoria de HELLER, vide BUZANELLO, José Carlos. "Constituição Política em Hermann Heller". Revista de Informação Legislativa. Brasília, n. 129, p. 259-265, jan./mar. 1996.

15 Vide, em maiores detalhes, a proposta dos cinco tipos ou momentos históricos apresentada em: JELLINEK, Georg. Teoria General Del Estado, cit.

16 DALLARI, Dalmo de Abreu. Elementos de Teoria do Estado, cit. p. 54.

17 CALMON, Pedro. Curso de Teoria Geral do Estado, cit. p. 45-46

18 ENGELS, Friedrich. A origem da Família, da Propriedade Privada e do Estado. Trabalho relacionado com as investigações de L. H. Morgan. Tradução de Leandro Konder. 14. ed. Rio de Janeiro : Bertrand Brasil, 1997, p. 165 e 166, respectivamente. Título original: Der Ursprung der Familie, des Privateigentaums und des Staats.

19 Especificamente quanto ao tema O Estado como Ente Territorial, vide CRUZ, Paulo Márcio. Fundamentos do Direito Constitucional. 2. ed. rev. amp. Curitiba: Juruá, 2003. p. 42-44.

20 HELLER, Herman. Teoria do Estado, cit. p. 159 

Contemporâneo.

Uma interessantíssima proposta sobre a passagem do Estado Moderno ao Estado Contemporâneo encontra-se em BRANDÃO, Paulo de Tarso. Ações Constitucionais: Novos Direitos e Acesso à Justiça, cit. p. 55 a 64.

31 Tenho adotado a noção de BEM COMUM registrada por MELO, Osvaldo Ferreira de. Dicionário de Direito Político. Rio de Janeiro: Forense, 1978. p. 12, e também em MELO, Osvaldo Ferreira de. Dicionário de Política Jurídica. Florianópolis:OAB/SC, 2000. p. 15. Aliás, em meu Livro O Estado e a Educação (Florianópolis: Estudantil, 1980),esquematizei o Bem Comum em sua estimulação, estrutura e conteúdo, e objetivo, colocando-o não somente como finalidade do Estado mas também como parâmetro regulador da intervenção do Estado no domínio educacional (e assim entendo deva ser com relação aos demais domínios ou segmentos de atuação do Estado), alçando-o a fator de estimulação da atuação dinâmica da Sociedade.

32 Veja "um conceito de Estado de Bem-estar para a operação científica" em, CRUZ, Paulo Márcio. Política, Poder, Ideologia e Estado Contemporâneo. Florianópolis: Diploma Legal, 2001. p. 207.

33 Vide POULANTZAS, Nicos. O Estado, o Poder, o Socialismo. Tradução de Rita Lima. 2. ed. Rio de Janeiro: Graal, 1985. p. 213. Título original: L’État, le Pouvoir, le Socialisme.

Recomendo a leitura de ROSANVALLON, Pierre. La crise de l'État-providence. Nouvelle edition.Editions du Seuil,1992. A frase inicial deste livro é: "L'État-providence est malade" (p.7).

35 Conforme consta em : PASOLD, Cesar Luiz. Personalidade e Comunicação, 2. ed. rev.amp. Florianópolis: Plus Saber Editora, 2005, p. 99. Também em: PASOLD, Cesar Luiz. $O$ advogado e a advocacia, 3. ed. rev. atual.amp.Florianópolis: OAB/SC Editora, 2001 p.141.

36 Conforme consta em : PASOLD, Cesar Luiz. Personalidade e Comunicação. cit. p.99- nota de rodapé. $n^{\circ}$ 58. Também em: PASOLD, Cesar Luiz. O advogado e a advocacia, cit. p.140.

37 Para os efeitos deste ensaio proponho seja compreendida a Ideologia como uma forma de encarar e conduzir as Relações Humanas sob a égide do Poder. A título de ilustração noticio aqui que oito conceitos operacionais distintos para a categoria IDEOLOGIA são encontrados em MACRIDIS, Roy C. Ideologias Políticas Contemporâneas: Movimentos e Regimes. Tradução de Luís Tupy Caldas de Moura e Maria Inês Caldas de Moura. Brasília: Editora UnB, 1982. p. 18-20. Título original: Contemporary political ideologies: movements and regimes. Outra percepção conceitual panorâmica, a partir de LUHMANN, encontra-se em: FERRAZ JÚNIOR, Tercio Sampaio. Teoria da Norma Jurídica: Ensaio de Pragmática da Comunicação Normativa. Rio de Janeiro: Forense, 1999. p. 155. Sobre as origens, desenvolvimento e significados de ideologia, vide WOLKMER, Antonio Carlos. Ideologia, Estado e Direito. 2. ed. rev. amp. São Paulo: Revista dos Tribunais, 1995. p. 91-107. Quanto à concepção marxista de ideologia, vide CHAUÍ, Marilena. O que é Ideologia. São Paulo: Abril Cultural/Brasiliense, 1984. p. 32-125. 
BOBBIO, Norberto. A Teoria das Formas de Governo. 2. ed. Tradução de Sérgio Bath. Brasília: Editora UnB, 1980. p. 27. Título original: La Teoria delle Forme di Governo nella Storia del Pensiero Político: Anno Accademico 1975-76.

39 Sobre os Direitos Sociais Fundamentais em sua complexidade constitucional vide, MARTINS NETO, João dos Passos. Direitos Fundamentais: Conceito, Função e Tipos. São Paulo: Revista dos Tribunais, 2003, em especial, p.166 e ss.

40 Vide precisa e elucidativa lição sobre a Constituição Mexicana de 1917 em COMPARATO, Fábio Konder. A Afirmação Histórica dos Direitos Humanos. 2. ed. rev. e ampl. São Paulo: Saraiva, 2001, especialmente, p.183-194. Na mesma obra, sobre a Constituição Alemã de 1919, vide p. 195-205.

41 MÉXICO. Constitucion Política de los Estados Unidos Mexicanos. 75. ed. México: Editorial Porrua, 1984.

42 Tradução livre da Bacharel em Administração e Acadêmica de Direito JAQUELINE MORETTI QUINTERO, a quem agradeço.

43 COMPARATO, Fábio. A Afirmação Histórica dos Direitos Humanos. cit. p.187.( sem o destaque no original).

44 Em URBINA, Alfredo Uerba. Nuevo Derecho Internacional Social. México: Porrua, 1979, p. 9 (maiúsculas no original).

45 Infelizmente as três Constituições citadas tiveram vigência e vigor em pequena duração temporal.

46 Exemplos históricos: na Constituição da Itália, (art. 1ํ); Constituição da República Popular de Moçambique (art. $3^{\circ}$ ); Constituição da República Portuguesa (art. 2o․, e item 4 do art. 3o); Constituição da República Democrática Alemã (art. 2‥ e item 2 do art. 5‥); Constituição da França (art. 3ํ., parágrafo primeiro); e no próprio preâmbulo da Constituição dos Estados Unidos da América .Conforme os textos constantes In MIRANDA, Jorge ( org. e trad.). Constituições de Diversos Países. Lisboa: Imprensa Nacional/ Casa da Moeda, 1979 (2 v.), p. 9 (v. 2); 156 (v. 2); 19 (v. 1); 308 (v.1) 277 (v. 1), respectivamente.

47 Também exemplos históricos: na Lei Constitucional da República Popular de Angola (art. 1)); Constituição da República Popular da China (art. 11); na então Lei Fundamental da República Federal da Alemanha (preâmbulo) ; Constituição da Venezuela (art. 72); Constituição da Federação Suíça (art. $2^{\circ}$.) Conforme textos constantes in Constituições de Diversos Países, cit., p. 65 (v. 1); 203 (v. 1); 43 (v 1); 381, 382 (v. 2); 301 (v. 2). A diferenciação dos Países eleitos para exemplificar neste aspecto, com relação aos mencionados como exemplos históricos no aspecto anterior, procura apenas ilustrar a universalidade das consagrações formais a respeito dos assuntos enfocados - origem do Poder estatal e compromisso com a Sociedade - os quais aliás guardam ou deveriam guardar profunda relação entre si, como pleiteio.

48 HEADY, Ferrel. Administração Pública: uma Perspectiva Comparada. Tradução de J. R. Brandão Azevedo. Rio de Janeiro: Zahar Editores, 1970. Título original: Public Administration: a Comparative Perspective.

49 Conforme POULANTZAS, Nicos. O Estado, o Poder, o Socialismo, cit. p. 259. De outra parte, na p. 246, esse Autor afirma que, "o estatismo autoritário é também a verdade que surge dos escombros do mito do Estado-Providência ou do Estado do bem-estar".

50 Vide a questão da Globalização sob diversos aspectos em ARRUDA JÚNIOR, Edmundo Lima de, e RAMOS, Alexandre (org.). Globalização, Neoliberalismo e o Mundo do Trabalho. Curitiba: IBEJ, 1998.

51 ELLSWORTH, P. T. A Economia Internacional. Tradução de José Luiz Silveira Miranda. São Paulo: Atlas, 1971. p. 15. (sem acesso ao título original no exemplar utilizado ).

\section{REFERÊNCIAS}

ARRUDA JÚNIOR, Edmundo Lima de, e RAMOS, Alexandre (org.). Globalização, Neoliberalismo e o Mundo do Trabalho. Curitiba: IBEJ, 1998.

BOBBIO, Norberto. A Era dos Direitos. Tradução de Carlos Nélson Coutinho. 5 reimp. Rio de Janeiro: Campus, 1992. p. 68.Título original: L' Etàt dei Diritti. 
A Teoria das Formas de Governo. 2. ed. Tradução de Sérgio Bath. Brasília: Editora UnB,1980. Título original: La Teoria delle Forme di Governo nella Storia del Pensiero Político: Anno Accademico 1975-76.

BRANDÃO, Paulo de Tarso. Ações Constitucionais: novos direitos e acesso à justiça. 2 ed. rev. amp. Florianópolis: OAB/SC Editora, 2006.

BUZANELLO, José Carlos. Constituição Política em Hermann Heller. Revista de Informação Legislativa. Brasília, n. 129, p. 259-265, jan./mar. 1996.

CADEMARTORI, Luiz Henrique Urquhart. Discricionariedade Administrativa no Estado Constitucional de Direito. Curitiba: Juruá, 2001.

CALMON, Pedro. Curso de Teoria Geral do Estado. Rio/São Paulo: Freitas Bastos, 1964.

CHAUÍ, Marilena. O Que é Ideologia. São Paulo: Abril Cultural/Brasiliense, 1984.

COMPARATO, Fábio Konder. A Afirmação Histórica dos Direitos Humanos. 2. ed. rev. e ampl. São Paulo: Saraiva, 2001.

CRUZ, Paulo Márcio. Fundamentos do Direito Constitucional. 2. ed. rev. amp. Curitiba: Juruá, 2003.

CRUZ, Paulo Márcio. Política, Poder, Ideologia e Estado Contemporâneo. Florianópolis: Diploma Legal, 2001.

DALLARI, Dalmo de Abreu. Elementos de Teoria Geral do Estado. 13. ed. São Paulo: Saraiva, 1987.

DALLARI, Dalmo de Abreu. Da Atualização do Estado. São Paulo: Edição do Autor, 1963.

ELLSWORTH, P. T. A Economia Internacional. Tradução de José Luiz Silveira Miranda. São Paulo: Atlas, 1971.

ENGELS, Friedrich. A origem da Família, da Propriedade Privada e do Estado. Trabalho relacionado com as investigações de L. H. Morgan. Tradução de Leandro Konder. 14. ed. Rio de Janeiro: Bertrand Brasil, 1997. Título original: Der Ursprung der Familie, des Privateigentaums und des Staats.

FERRAZ JÚNIOR, Tercio Sampaio. Teoria da Norma Jurídica: Ensaio de Pragmática da Comunicação Normativa. Rio de Janeiro: Forense, 1999.

HEADY, Ferrel. Administração Pública: uma Perspectiva Comparada. Tradução de J. R. Brandão Azevedo. Rio de Janeiro: Zahar Editores, 1970. Título original: Public Administration: a Comparative Perspective.

HELLER, Herman. Teoria do Estado. Tradução de Lycurgo Gomes da Motta. São Paulo: Mestre Jou, 1968. Título original: Staatslehre.

JELLINEK, Georg. Teoria General Del Estado. Tradução de Fernando de Los Rios Urruti. México: D. F. Compañia Editorial Continental , s.d.

MACRIDIS, Roy C. Ideologias Políticas Contemporâneas: Movimentos e Regimes. Tradução de Luís Tupy Caldas de Moura e Maria Inês Caldas de Moura. Brasília: Editora UnB, 1982. Título original: Contemporary political ideologies: movements and regimes 
MARTINS NETO, João dos Passos. Direitos Fundamentais: Conceito, Função e Tipos. São Paulo: Revista dos Tribunais, 2003.

MARTINS NETO, João dos Passos. Não-Estado e Estado no Leviatã de Hobbes. Florianópolis: OAB/SC Editora, 1999.

MELO, Osvaldo Ferreira de. Dicionário de Direito Político. Rio de Janeiro: Forense, 1978.

MELO, Osvaldo Ferreira de. Dicionário de Política Jurídica. Florianópolis: OAB/SC Editora, 2000.

MÉXICO. Constitucion Política de los Estados Unidos Mexicanos. 75. ed. México: Editorial Porrua, 1984.

MIRANDA, Jorge (org. e trad.). Constituições de diversos Países. Lisboa: Imprensa Nacional/ Casa da Moeda, 1979. 2 v.

MIRANDA, Jorge. Teoria do Estado e da Constituição. Rio de Janeiro: Forense, 2002.

OLIVEIRA JÚNIOR, José Alcebíades de. Teoria Jurídica e Novos Direitos. Rio de Janeiro: Lumen Juris, 2000.

PASOLD, Cesar Luiz. Novos Direitos: Conceitos Operacionais de cinco Categorias que Ihe são conexas. In: Revista Seqüência, no 50, p. 225-236, jul. 2005.

PASOLD, Cesar Luiz. Prática da Pesquisa Jurídica e Metodologia da Pesquisa Jurídica. 10. ed. rev. amp. Florianópolis: OAB/SC Editora, 2007

Personalidade e Comunicação. 2. ed. rev. amp. Florianópolis: Plus Saber Editora, 2005.

Função Social do Estado Contemporâneo. 3. ed. rev. atual. amp. Florianópolis: OAB/SC Editora co-edição Editora Diploma Legal. 2003.

. O Advogado e a Advocacia. 3. ed. rev. atual. amp. Florianópolis: OAB/SC Editora, 2001

. O Estado e a Educação. Florianópolis: Lunardelli, 1980.

POULANTZAS, Nicos. O Estado, o Poder, o Socialismo. Tradução de Rita Lima. 2. ed. Rio de Janeiro: Graal, 1985. Título original: L`État, lể Pouvoir, lê Socialisme.

ROSANVALLON, Pierre. La crise de l'État-providence. Nouvelle edition.Editions du Seuil,1992.

SOUZA, José Pedro Galvão de. O Estado Tecnocrático. São Paulo: Saraiva, 1973.

URBINA, Alfredo Uerba. Nuevo Derecho Internacional Social. México: Porrua, 1979.

WOLKMER, Antonio Carlos. Ideologia, Estado e Direito. 2. ed. rev. amp. São Paulo: Revista dos Tribunais, 1995. 
Recebido para publicação 06/06/2008

Aceito para publicação 23/12/2008 